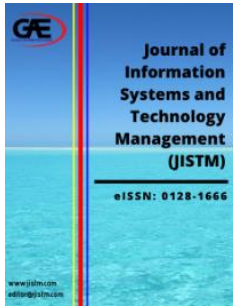

\author{
JOURNAL OF INFORMATION \\ SYSTEM AND TECHNOLOGY \\ MANAGEMENT (JISTM) \\ WWW.jistm.com
}

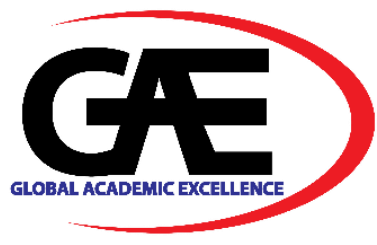

\title{
A COMPARISON BETWEEN TIDAL CONSTITUENTS DERIVED FROM SATELLITE ALTIMETRY AND IN-SITU DATA AROUND PENINSULAR MALAYSIA
}

\author{
Mohammad Hanif Hamden ${ }^{1 *}$, Ami Hassan Md Din ${ }^{1,2}$, Dudy Darmawan Wijaya ${ }^{3}$
}

1 Geospatial Imaging and Information Research Group (GI2RG), Faculty of Built Environment and Surveying, Universiti Teknologi Malaysia, Johor, Malaysia

Email: mhanif87@live.utm.my

2 Geoscience and Digital Earth Centre (INSTEG), Faculty of Built Environment and Surveying, Universiti Teknologi Malaysia, Johor, Malaysia

Email: amihassan@utm.my

3 Geodesy Research Division, Faculty of Earth Science and Technology, Institute of Technology Bandung, Jl. Ganesha 10, Bandung, Malaysia

Email: dudy@gd.itb.ac.id

* Corresponding Author

\section{Article Info:}

Article history:

Received date: 01.10.2021

Revised date: 01.11.2021

Accepted date: 20.11 .2021

Published date: 01.12.2021

To cite this document:

Hamden, M. H., Md Din, A. H., \& Wijaya, D. D. (2021). A Comparison Between Tidal Constituents Derived From Satellite Altimetry And In-Situ Data Around Peninsular Malaysia. Journal of Information System and Technology Management, 6 (24), 139. 151.

DOI: $10.35631 / J I S T M .624015$

This work is licensed under CC BY 4.0

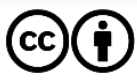

Abstract:

Satellite altimetry technology has been widely used in exploring Earth's Ocean activities. Achieving a remarkable accuracy in measuring sea level for ocean tide analysis has led the local researchers to investigate more details on tidal behaviour in the regional area. This study is an attempt to assess the reliability of derived tidal constituents between satellite radar altimetry and in-situ data which is referred to as coastal tide gauges. Three satellite missions denoted as TOPEX class missions namely TOPEX, Jason-1, and Jason-2 were used to derive along-track sea surface height ( $\mathrm{SSH}$ ) time series over 23 years. Besides, four selected coastal tide gauges were used for tidal analysis and validation where the tidal data have at least 19 years of hourly observation. Derivation of tidal constituents from both satellite altimetry and tide gauges were executed by adopting the harmonic analysis method. The comparisons were made by calculating the Root Mean Square Misfit (RMSmisfit) of each tidal constituent between the nearest altimetry point to the tide gauges. After RMSmisfit, Root Sum Square (RSS) values of tidal constituents at each tide gauge were also calculated. The results displayed the RMSmisfit of tidal constituents agreed well with the selected tide gauges which are within $10 \mathrm{~cm}$ except for M2 constituents which recorded $10.2 \mathrm{~cm}$. Pelabuhan Kelang tide gauge station showed the highest RSS value followed by Pulau Langkawi which recorded $21.2 \mathrm{~cm}$ and $9.8 \mathrm{~cm}$, respectively. In conclusion, overall results can be inferred that the satellite-derived tidal constituents are likely to have good agreement 


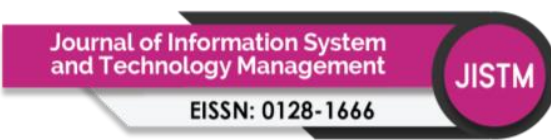

Volume 6 Issue 24 (December 2021) PP. 139-151

DOI: 10.35631/JISTM.624015

with the selected tide gauge stations. Nevertheless, further analysis should be executed in determining high precision satellite-derived tidal constituents, especially in the complex regional area.

Keywords:

Satellite Altimetry, Tide Gauge, Tidal Constituents, Harmonic Analysis, Comparison

\section{Introduction}

Tide is defined as the rise and fall of sea level which influence by the gravitational attraction between the moon, the earth and the sun. Generally, tides can be modelled by using three methods namely, hydrodynamic modelling, empirical modelling and integration between hydrodynamic model and empirical model (Fok, 2012; Pirooznia et al., 2016; Soltanpour et al., 2017). Before the revolution of satellite radar altimetry technique, tides were analysed and modelled using in-situ measurements which normally referred to tide gauge data. Based on the authors' knowledge, some constraints occurred when tidal analysis is only relied on tide gauges. This is due to the installation of tide gauges usually focussed on the coastal area. Thus, the tide models beyond the coastal area are still undetermined and the values commonly based on the assumption with the nearest in-situ data. Not only that, if the distributions of coastal tide gauges are not dense enough, the determination of tidal behaviour in the particular area would also be less accurate.

A wide range of ocean activities have been expanded with the advent of satellite altimetry technology. Satellite altimetry has become an essential platform for investigating the Earth's ocean. According to Cazenave (2019), the data measured from satellite altimetry have supported valuable information in Earth sciences domains as well as it revolutionised the knowledge of marine gravity field, ocean tides dynamics, ocean circulation and climate change in respect to sea level rise. Moreover, satellite altimetry also has been used by several researchers to study the ocean activities in a particular region. Hamid et al. (2018), for instance, utilised altimetry data to analyse sea level rates in Malaysia. Subsequently, Din et al. (2019) performed further investigation to measure sea level and vertical land motion (VLM) in Malaysia using multi-mission sensors, including satellite altimetry. Since 1993, satellite altimetry missions have achieved remarkable accuracy in the measurement sea level for ocean tide analysis. This is due to its high precision of orbit and improvement of most recent geophysical corrections.

It is undeniable that the long-term sea level observation from tide gauges can enhance the knowledge of tides. However, these measurements are limited as they measured only near the coast (Gomis et al., 2012). As a result, ocean tide analysis based on tide gauges in the open ocean is limited, leaving tidal characteristics beyond the shore uncertain. Furthermore, advances in altimetry measurement have demonstrated that this platform is routinely used to record global sea level variations with great precision and high spatial-temporal resolution (Feng and Jin, 2015; Salameh et al., 2018). This led to the acquisition of the SSH data from altimetry can be served as tide gauge measurements at each location globally (Fok, 2012).

To this end, the ocean tide can be explored over Malaysian seas since this study is focused on the regional area around the Peninsular Malaysia. Peninsular Malaysia also known as West Malaysia is enclosed by Malacca Straits and South China Sea (SCS). According to Gunathilaka Copyright $\odot$ GLOBAL ACADEMIC EXCELLENCE (M) SDN BHD - All rights reserved 
and Mahmud (2014), the Malacca Straits is a tidally complex area with varies of tidal range patterns and values. Daryabor et al. (2016), on the other hand, claims that the SCS has complex bathymetry and tidal dynamics. As the geography of Peninsular Malaysia is surrounded by many small islands as well as located at intricated area for tidal system, it would give a great challenge towards satellite altimetry application in estimating the tidal characteristics within the study area.

Henceforth, this study aims to compare the reliability of satellite radar altimetry derived tidal constituents (SDTC) with the coastal tide gauges derived tidal constituents. Derivation of tidal constituents were performed by adopting harmonic analysis method on both altimetry and tide gauge data. The harmonic constants of four major tidal constituents namely M2, S2, K1 and O1 were utilised for the purpose of assessment. The comparison is based on the selected coastal tide gauge stations and the nearest along track satellite derived tidal constituents to the tide gauges. Further details regarding to the data and method used in this study are explained in the next section.

\section{Methodology}

\section{Area of Study}

As aforementioned, the geographical boundary in this study is limited between $0^{\circ} \mathrm{N}-9^{\circ} \mathrm{N}$ latitude and $98^{\circ} \mathrm{E}-106^{\circ} \mathrm{E}$ longitude as illustrated in Figure 1. From Figure 1, it can be clearly seen that Peninsular Malaysia is enclosed with Malacca Straits at the west and South China Sea at the east. Strait of Tebrau is situated at the southern of Peninsular Malaysia while Gulf of Thailand is located at the northeast of Peninsular Malaysia. No altimetry track can be observed within the Strait of Tebrau due to the narrow channel between southern of Malaysia and Singapore. Gulf of Thailand is likely to be not obviously to be seen as the study area is limited within the stated geographical coordinate. Thus, the study area is only focus in estimating the tidal constituents around Malacca Straits and South China Sea. Triangle points along the coast of Peninsular Malaysia indicates the distribution of Department of Surveying and Mapping Malaysia (DSMM) tide gauges. The circles indicate the selected tide gauges used in the assessment with SDTC.

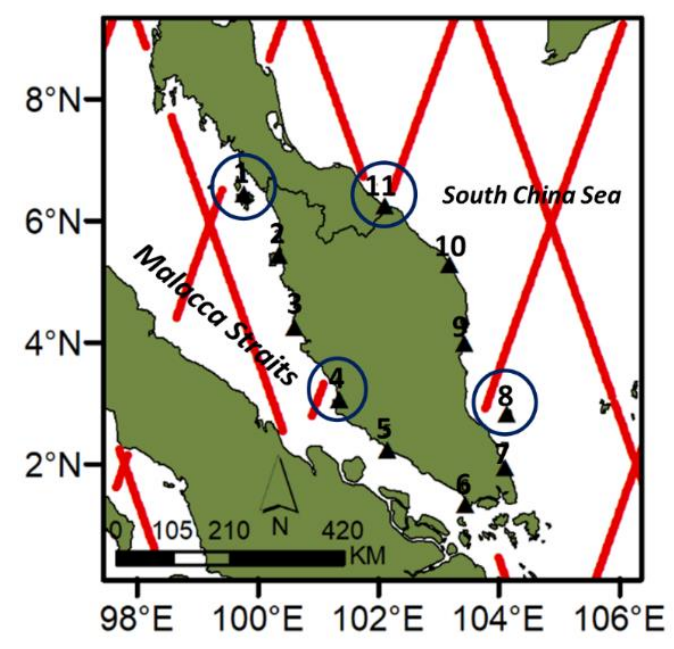

Figure 1: Along Track TOPEX Class Mission (Red) Within The Study Area. Black Triangles Represent The Distribution of DSMM Coastal Tide Gauges Along Peninsular Malaysia 


\section{Satellite Altimetry and In-Situ Datasets}

To obtain the along track harmonic constants of four major tidal constituents, the sea surface height (SSH) time series were derived and analysed at the corresponding study area. Derivation of SSH from satellite altimetry can be obtained using equation (1) (Ainee, 2016; Hamid et al., 2018; Din et al., 2019).

$h_{S S H}=H_{a l t}-R_{o b s}-\left(h_{d r y}+h_{w e t}+h_{\text {ion }}+h_{D A C}+h_{\text {ocean }}+h_{\text {sol }}+h_{\text {pole }}+h_{s s b}\right)$

where, $h_{S S H}$ is the corrected sea surface height, $H_{\text {alt }}$ is the satellite altitude, $R_{o b s}$ is the altimeter range measurement, $h_{d r y}$ is the dry tropospheric correction, $h_{w e t}$ is the wet tropospheric correction, $h_{\text {ion }}$ is the ionospheric correction, $h_{D A C}$ is the dynamic atmospheric correction, $h_{\text {ocean }}$ is the ocean tide correction,,$h_{\text {sol }}$ is the solid earth tide correction, $h_{\text {pole }}$ is the pole tide correction, and $h_{s s b}$ is the sea state bias correction. The SSH time series were computed by applying the best range and geophysical corrections within the study area. The range and geophysical were adopted from Din et al. (2014) as shown in Table 1. However, $h_{\text {ocean }}$ must not be applied into the equation as ocean tide is the signal of interest in this study.

Table 1: List of Corrections Applied to SSH Measurements

\begin{tabular}{ccc}
\hline & Correction / Model & Status \\
\hline Orbit/Gravity field & EIGEN GL04C & Applied \\
Dry Troposphere & ECMWF & Applied \\
Wet Troposphere & Radiometer & Applied \\
Ionosphere & Smooth dual-frequency & Applied \\
Dynamic Atmosphere & MOG2D & Applied \\
Ocean Tide & - & Not Applied \\
Solid Earth Tide & Elastic response to tidal potential & Applied \\
Pole Tide & Tide produced by Polar Wobble & Applied \\
Sea State Bias & CLS non-parametric & Applied \\
\hline
\end{tabular}

Three satellite missions were utilised to estimate tidal constituents such as TOPEX, Jason-1 and Jason-2. All of these missions expressed as TOPEX class missions move along within the same orbit but measure the data at different time. Thus, the estimation of the tidal constituents in this study are carried out by combining all the temporal data which supplementing relatively 23 years of joint TOPEX class missions. Satellite altimetry data were obtained from Radar Altimeter Database System (RADS) as shown in Table 2. Cycle number in the table refers to satellite repetitively or repeat orbit.

Table 2: Satellite Altimetry Missions Involved

\begin{tabular}{ccccc}
\hline Satellite & Phase & Cycle & Mission & Period Time \\
\hline TOPEX & A & $001-364$ & ERM & January 1993 - August 2002 \\
Jason-1 & A & $001-260$ & ERM & January 2002 - January 2009 \\
Jason-2 & A & $001-303$ & ERM & July 2008 - October 2016 \\
\hline
\end{tabular}

Notes:

ERM indicates Exact Repeat Mission 
According to Kamaruddin et al. (2016), the DSMM had established 21 tide gauge stations since 1984 where 12 tide gauges were located along Peninsular Malaysia and 9 tide gauges were located along East Malaysia. In present, a total of eleven tide gauge stations were installed along the Peninsular Malaysia. However, only four selected tide gauges were used for the comparison with the SDTC because the selected tide gauges were located to the nearest altimetry track in this study. All tidal observations network installed by DSMM observe tide continuously for at least 19 years since 1984. The selected tide gauges for comparison with the nearest altimetry track are highlighted in blue circle in Figure 1.

\section{Harmonic Analysis Method}

Before performing harmonic analysis, the SSH times series from TOPEX class missions must be derived by applying the best range and geophysical corrections within the study area. The range and geophysical corrections were adopted from Din et al. (2014). Nevertheless, only ocean tide correction was not applied to the SSH time series as the tidal signal is the interest of this study. Later, the four major tidal constituents at each along track satellite altimetry points were estimated by using harmonic analysis formula as displayed in equation (2) (Ainee, 2016; Alihan, 2018).

$$
H(t)=Z_{0}+\sum_{n} A m p \cos (\omega t-\varphi)
$$

where, $H(t)$ is the SSH observation data; $Z_{0}$ is the mean sea level (MSL); $A m p$ is the amplitude of each tidal constituents; $\omega$ is the angular speed of each tidal constituents and $\varphi$ is the phase delay of each tidal constituents. Based on equation (2), the coefficient of $Z_{0}, A m p$ and $\varphi$ of tidal constituents must be estimated. Thus, this equation is linearised using trigonometric identities as expressed in equation (3) (Katznelson, 2004; Wijaya, 2012; Alihan, 2018).

$$
H(t)=Z_{0}+\sum_{n} A m p[\cos \omega t \cdot \cos \varphi+\sin \omega t \cdot \sin \varphi]
$$

Assuming $a$ and $b$ as the coefficients of series as follows:

$$
a=A m p \cos \varphi \quad, \quad b=A m p \sin \varphi
$$

Then, substitute equation (4) into equation (3) to express the periodic functions as shown in equation (5).

$$
H(t)=Z_{0}+\sum_{n} a \cos \omega t+b \sin \omega t
$$

The coefficient of $Z_{0}, a$ and $b$ can be estimated using least square estimation as expressed in equation (6) by harmonic analysis (Wijaya, 2012; Thomson and Emery, 2014; Ainee, 2016; Alihan, 2018).

$$
\begin{gathered}
A X=l \\
\left(A^{T} A\right) X=A^{T} l \\
X=\left(A^{T} A\right)^{-1} A^{T} l
\end{gathered}
$$


Thus, the Amp and $\varphi$ of tidal constituents can be obtained using trigonometric functions as expressed in equation (7).

$$
A m p=\sqrt{a^{2}+b^{2}} \text { and } \varphi=\tan ^{-1} \frac{b}{a}
$$

\section{Data Verification}

Comparison between SDTC with coastal tide gauges were performed in term of Root Mean

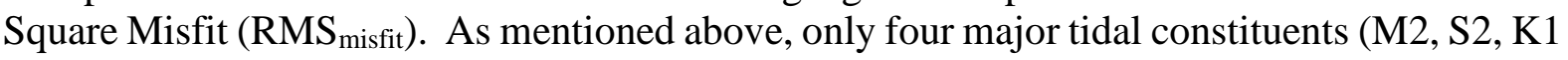
and $\mathrm{O1}$ ) were used to compared with coastal tide gauge stations. $\mathrm{RMS}_{\text {misfit }}$ was implemented to measure the difference between amplitude and phase of tidal constituents from satellite altimetry and tide gauges. RMS misfit was calculated based on the equation (8) (Daher et al., 2015; Fu et al., 2020). After RMS misfit computation, Root Sum Square (RSS) was calculated for the overall tide models generated from this study. The formula of RSS is described as in equation (9).

$$
\begin{gathered}
R M S_{\text {misfit }}=\left\{\frac{1}{2 N} \sum_{k=1}^{N}\left[\left(A_{o} \cos G_{o}-A_{m} \cos G_{m}\right)^{2}+\left(A_{o} \sin G_{o}-A_{m} \sin G_{m}\right)^{2}\right]\right\}^{\frac{1}{2}} \\
R S S=\left(\sum_{l=1}^{M} R M S_{l}^{2}\right)^{\frac{1}{2}}
\end{gathered}
$$

where, $A_{o}$ and $G_{o}$ are the amplitude and phase estimated from satellite altimetry. Meanwhile, $A_{m}$ and $G_{m}$ are the amplitude and phase produced by tide gauges. $N$ indicates the number of assessment samples. $M$ represents the total tidal constituents used in this study.

\section{Results and Discussion}

\section{Along Track TOPEX Class Derived Tidal Constituents}

Harmonic analysis method has been adopted in this study to analyse the SSH time series from 23 years of TOPEX class mission. The tidal analysis is done to estimate the selected four major tidal constituents (M2, S2, K1 and O1). Only four tidal constituents are estimated in this study because these tidal constituents can be used to determine the tidal types such as semi-diurnal, diurnal and mixed tides based on the ratio of amplitudes, $(\mathrm{K} 1+\mathrm{O} 1)(\mathrm{M} 2+\mathrm{S} 2)-1$, as introduced by Courtier (1983). Besides, as referred to DSMM Tide Observation Record, these four constituents are the most dominant component of tide at most of the Malaysian seas. Figure 2 illustrates the along track at each point of TOPEX class derived tidal constituents. It can be clearly seen that the amplitudes of M2 and S2 are greater in Malacca Straits compared to South China Sea. However, the $\mathrm{K} 1$ and $\mathrm{O} 1$ are vice versa from the M2 and S2 characteristics. This can be inferred that the classification of tide at Malacca Straits is most likely semi-diurnal tide while at South China Sea is either mixed diurnal tide or diurnal tide. The assumptions of classification tides are aligned with the statement from Hoe (1996) where Peninsular Malaysia is dominated by semi-diurnal tide and mixed dominant semi-diurnal except for the Cendering station which has mixed dominant diurnal tide. Cendering station is located at the east of Peninsular Malaysia facing the South China Sea. The classification of tides can be further proven by calculating the form factor or Courtier coefficient (CC) suggested by Courtier (1983). Semidiurnal, semidiurnal with diurnal inequality, mixed, and diurnal tides are 
classified by the $\mathrm{CC}$ ratio when $0<\mathrm{CC} \leq 0.25,0.25<\mathrm{CC} \leq 1.5,1.5<\mathrm{CC} \leq 3.0$, and $\mathrm{CC}>3.0$, respectively.

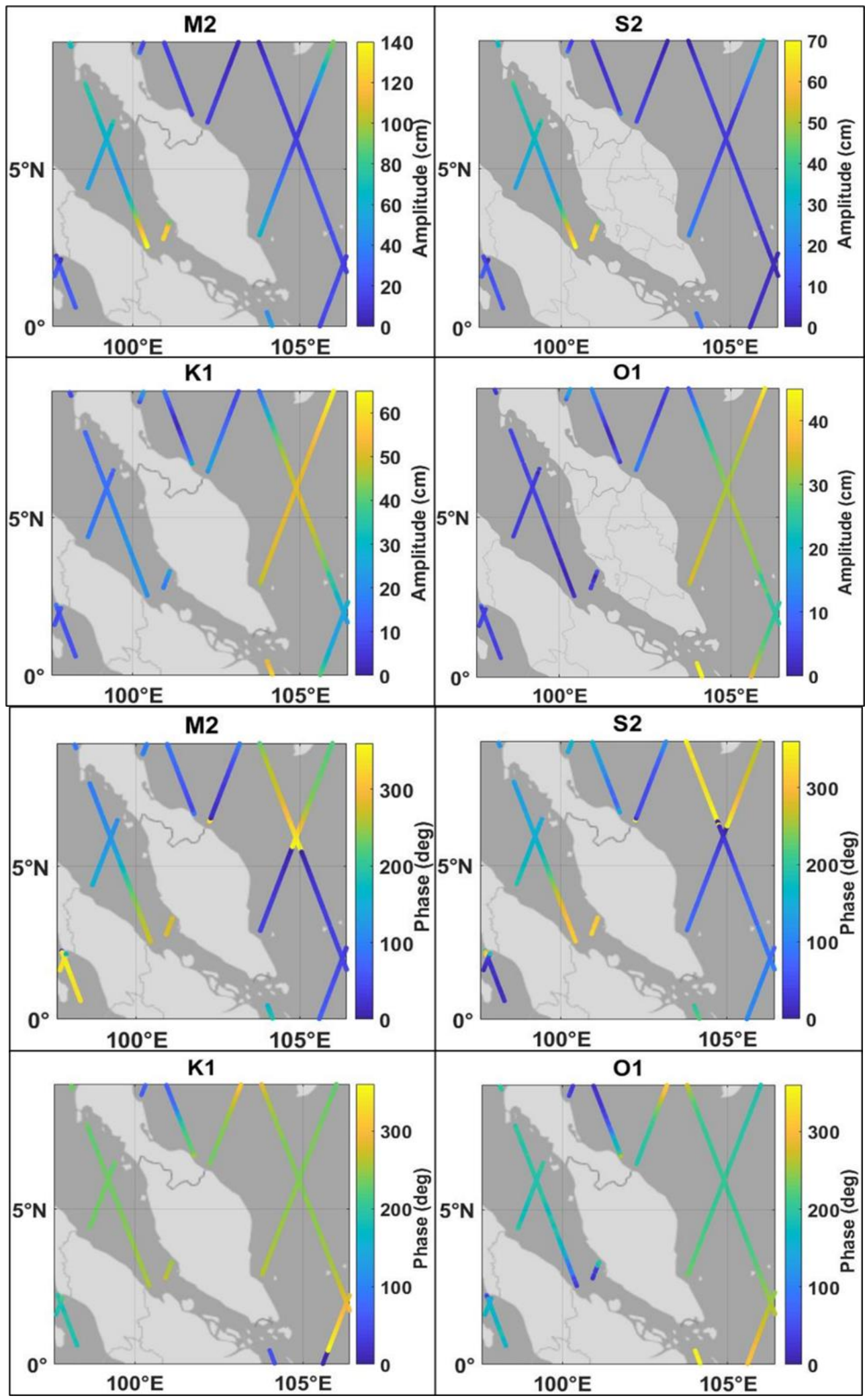

Figure 2: Along Track Satellite (TOPEX class) Derived Amplitude (Top) and Phase (Bottom) of Four Major Tidal Constituents 


\section{Comparison with Coastal Tide Gauge Stations}

DOI: 10.35631/JISTM.624015

Tidal data from four selected tide gauge stations were used for comparison with the nearest altimetry track. Table 3 shows the locations and distances between tide gauge stations and the nearest altimetry track. Geting station showed the longest distance between tide gauge and altimetry point which is $42.56 \mathrm{~km}$ while the shortest distance was at Pelabuhan Kelang which is $36.02 \mathrm{~km}$. Notably that the linear distance is calculated based on two coordinate points.

Table 3: Location and Distance Between Tide Gauges and The Nearest Altimetry Track

\begin{tabular}{cccccc}
\hline Satellite & \multicolumn{2}{c}{ SDTC } & \multicolumn{2}{c}{ Tide Gauge } & Nearest \\
\cline { 2 - 5 } & Latitude & Longitude & Latitude & Longitude & Distance (km) \\
\hline P. Tioman & 2.904 & 103.794 & 2.807 & 104.138 & 39.70 \\
Geting & 6.568 & 102.278 & 6.226 & 102.105 & 42.56 \\
Pel. Klang & 3.150 & 101.048 & 3.051 & 101.356 & 36.02 \\
P. Langkawi & 6.497 & 99.417 & 6.425 & 99.765 & 39.26 \\
\hline
\end{tabular}

$\mathrm{RMS}_{\text {misfit }}$ of tidal constituents between the nearest altimetry track and tide gauges are shown in Figure 3. M2 constituent depicted the highest $\mathrm{RMS}_{\text {misfit }}$ at all tide gauges involved which is $10.2 \mathrm{~cm}$ followed by S2, K1 and O1 constituents which showed $5.7 \mathrm{~cm}, 1.7 \mathrm{~cm}$, and $1.5 \mathrm{~cm}$, respectively. Large value of $\mathrm{RMS}_{\text {misfit }}$ from M2 and S2 constituents are probably due to the complexity of the area in which the tide gauges were installed especially at Malacca Straits. According to Oreiro et al. (2014), the predicted RMS misfit grows in proportion to the tidal range. As Gunathilaka and Mahmud (2014) pointed out, the tidal range patterns in the Malacca Straits varies, hence the $\mathrm{RMS}_{\text {misfit }}$ may be greatly influenced by the tidal range of the location under consideration. Furthermore, tide models used to de-tide SSH are usually more accurate in deep water than near the coast or in the location where there are limited altimetry data. As in this case, it is due to the existence of small islands and a narrow channel.

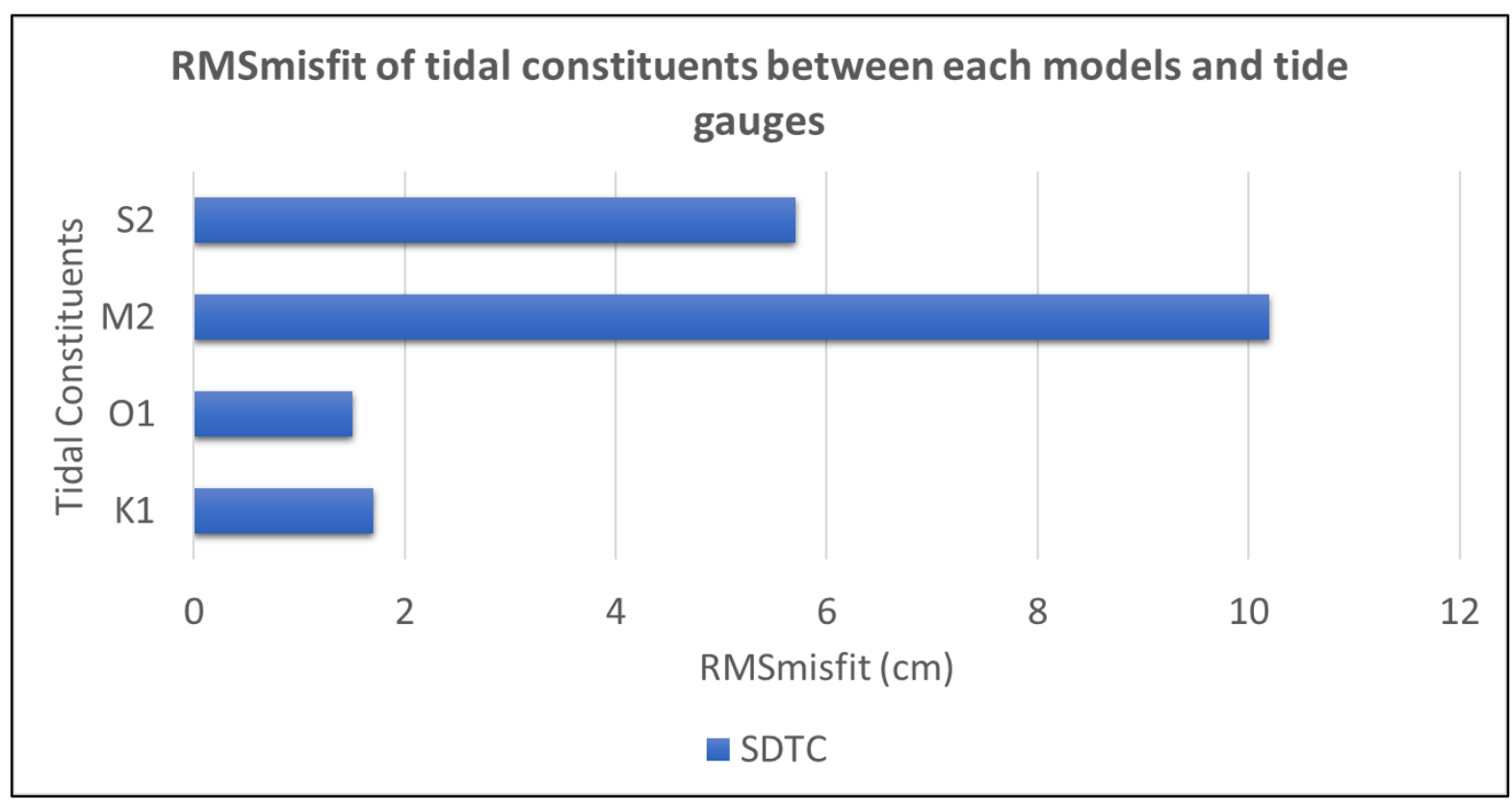

Figure 3: RMSmisfit of Four Tidal Constituents Between SDTC and Tide Gauge Stations 
RSS value of four major tidal constituents were computed as shown in Figure 4. The number on the top of the bar chart indicates the distance of the nearest altimetry point to the tide gauges. RSS values at Geting and Pulau Tioman showed high precision, which is within $5.0 \mathrm{~cm}$ and $5.3 \mathrm{~cm}$, respectively, followed by Pulau Langkawi which recorded RSS value of $9.8 \mathrm{~cm}$. Based on previous study by Fu et al. (2020), the computed RSS value at Pulau Langkawi is within $10-15 \mathrm{~cm}$ in which the nearest distance of altimetry track with tide gauge station is $39.37 \mathrm{~km}$. This can be inferred that the RSS value obtained from this study showed a significant improvement compared to previous study despite of having the approximately similar distance of nearest altimetry track with tide gauge. This might be due to the different corrections applied to the SSH altimetry measurement before the tidal analysis was performed. An appropriate RSS limit value should be specified. Based on Daher et al. (2015), it is assumed that the model results in the shallow-water zone are classified as satisfactory (or acceptable) if the RSS value is less than $12 \mathrm{~cm}$. Pelabuhan Kelang displayed the lowest precision where the RSS value is $21.2 \mathrm{~cm}$. Both tide gauges at Malacca Straits exhibited higher values of RSS values than South China Sea because this area is a closed and narrow sea channel and has shallow depth. This can be seen that Pelabuhan Kelang station which was located at the narrow channel of Malacca Straits and obstructed by few small islands as shown in Figure 5. These reasons are most likely caused the tidal constituents having a large gradient.

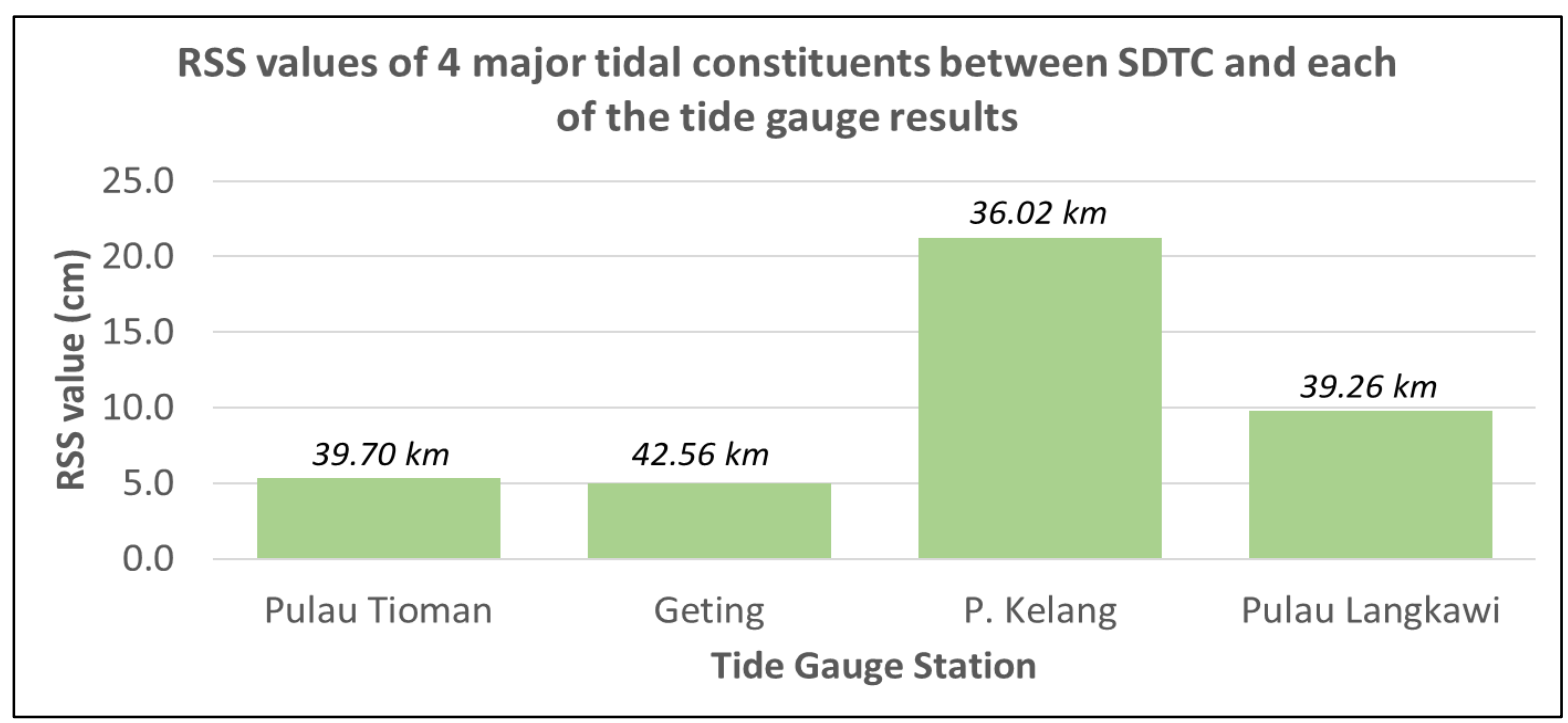

Figure 4: RSS Values of Four Major Tidal Constituents at Each Selected Tide Gauges 


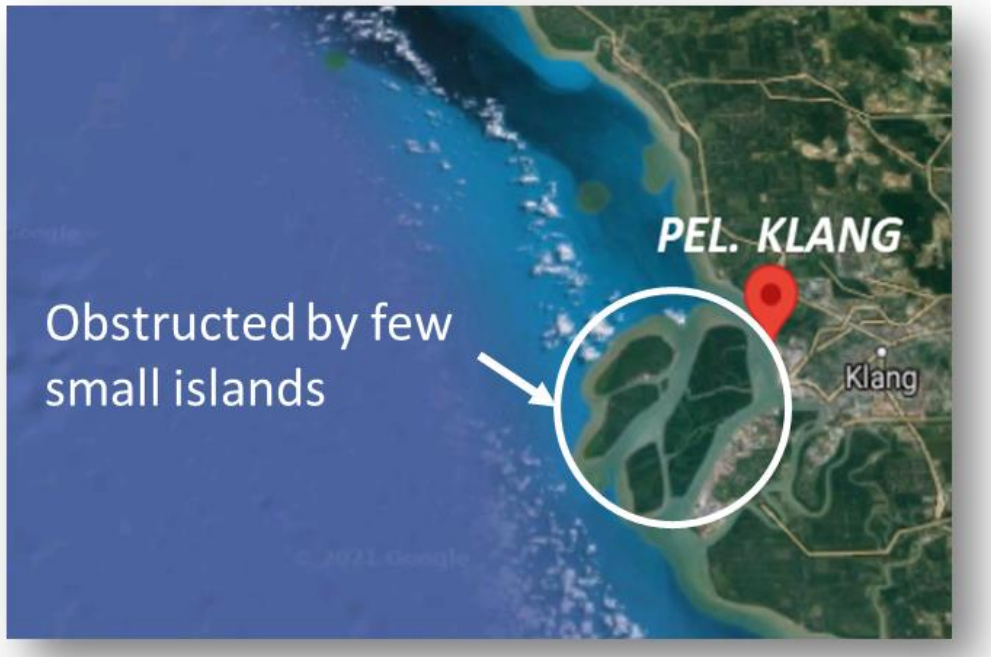

Figure 5: Obstruction of Few Small Islands Near Pelabuhan Klang Tide Gauge Station

\section{Consistency of Tidal Constituents at Ascending and Descending Pass}

Harmonic analysis is performed at the crossover of satellite altimetry track. This is to assess the consistency of satellite derived tidal constituents at the crossover of ascending and descending pass. It is essential to evaluate this consistency because satellite altimetry is usually moving along its orbit in ascending and descending track. The intersection between ascending and descending track called crossover point should obtained almost similar value of estimated tidal constituents. As observed in Figure 1, there are two crossover points identified where one point is at South China Sea and the other is at Malacca Straits. The statistical result of the crossover difference for each tidal constituent is tabulated in Table 4. The RMS amplitudes difference of four tidal constituents (M2, S2, K1 and O1) between ascending and descending track at both crossover points showed good agreement which is within the range of $0.16 \mathrm{~cm}$ to $0.52 \mathrm{~cm}$. In term of phases, the RMS difference values showed consistent results which is within $0.37^{\circ}$ to $1.32^{\circ}$. Therefore, it can be inferred that the satellite derived consistent tidal constituents along ascending and descending track as the RMS recorded small difference values. The outcomes showed promising result compared to the previous study by Ainee (2016). As the previous study only focused within the SCS area, the RMS amplitudes difference of four tidal constituents recorded $0.68 \mathrm{~cm}$ to $5.50 \mathrm{~cm}$ at four selected crossover points. Meanwhile, the RMS phases difference recorded $3.44^{\circ}$ to $155.71^{\circ}$.

Table 4: Statistical Result of Crossover Difference for Each Tidal Constituent

\begin{tabular}{ccccccccc}
\hline \multirow{2}{*}{ Region } & \multicolumn{4}{c}{ Amplitude (cm) } & \multicolumn{4}{c}{ Phase (deg) } \\
\cline { 2 - 9 } & M2 & S2 & K1 & O1 & M2 & S2 & K1 & O1 \\
\hline Malacca Straits & 0.31 & 0.45 & 0.31 & 0.39 & -1.91 & -0.32 & -0.34 & 0.53 \\
South China Sea & 0.27 & 0.12 & -0.09 & 0.98 & -1.83 & -0.97 & 1.42 & -0.53 \\
\hline Average & $\mathbf{0 . 2 9}$ & $\mathbf{0 . 2 8}$ & $\mathbf{0 . 1 1}$ & $\mathbf{0 . 6 8}$ & $\mathbf{- 1 . 8 7}$ & $\mathbf{- 0 . 6 4}$ & $\mathbf{0 . 5 4}$ & $\mathbf{0 . 0 0}$ \\
RMS & $\mathbf{0 . 2 9}$ & $\mathbf{0 . 2 3}$ & $\mathbf{0 . 1 6}$ & $\mathbf{0 . 5 2}$ & $\mathbf{1 . 3 2}$ & $\mathbf{0 . 5 1}$ & $\mathbf{0 . 7 3}$ & $\mathbf{0 . 3 7}$ \\
\hline
\end{tabular}

\section{Conclusion}

This paper studied an analogy between the satellite radar altimetry and tide gauges derived from four major tidal constituents which are M2, S2, K1 and O1. Before comparison was made, both satellite altimetry and tide gauge data were analysed to estimate the tidal constituents at the particular locations. SSH time series from TOPEX class consist of TOPEX, Jason-1 and 
Jason-2 missions were used in this study for tidal analysis. Harmonic analysis method was adopted for both data sources to estimate the tidal constituents. Four tide gauges were used for the purpose of comparison with the nearest altimetry points from tide gauges.

The comparison results showed that the $\mathrm{RMS}_{\text {misfit }}$ of each tidal constituent agreed well between each other where the values are less than $10 \mathrm{~cm}$ except for M2 constituents which recorded slightly more than $10 \mathrm{~cm}$. This might be due to the complexity area within the Malacca Straits, thus, contributing the RMS misfit $_{\text {to }}$ be larger. In term of RSS values at each tide gauge, Pulau Tioman and Geting have high precision of tidal constituents which exhibited within the range of $5 \mathrm{~cm}$. Tide gauge at Pelabuhan Kelang showed the highest RSS values followed by Pulau Langkawi which are $21.2 \mathrm{~cm}$ and $9.8 \mathrm{~cm}$ respectively. Both of these tide gauges located at Malacca Straits where its geography is a narrow channel that most likely contributed large gradient of tidal constituents. Apart from that, the satellite radar altimetry displayed good consistency in estimating the tidal constituents where the RMS crossover differences of amplitude and phase recorded the values of $0.16 \mathrm{~cm}-0.52 \mathrm{~cm}$ and $0.37^{\circ}-1.32^{\circ}$, respectively.

In conclusion, satellite altimetry is one of the important tools for exploring the ocean activities as well as it could assist in investigating the tidal behaviour in the open sea. This study proved that the satellite derived tidal constituents are agreed well to the coastal tide gauges. However, further studies need to be done to produce high precision tide models, for instance, by increasing the used of tide gauges as well as merging more satellite missions with different types of orbit track to increase the spatial resolution. Furthermore, it is also recommended to investigate the shallow-water tidal constituents in future studies especially in the shallow water where the dynamics become nonlinear and tidal spectra apparently seems to be more complicated.

\section{Acknowledgement}

The authors would like to acknowledge the TU Delft, NOAA, Altimetrics LLC for providing the satellite altimetry data through Radar Altimeter Database System (RADS). Special thanks also dedicated to the Department of Surveying and Mapping Malaysia (DSMM) for kindly distributing the tidal data for this study. This study is funded by the Ministry of Higher Education (MOHE) under the Fundamental Research Grant Scheme (FRGS) Fund, Reference Code: FRGS/1/2020/WAB05/UTM/02/1 (UTM Vote Number: R.J130000.7852.5F374).

\section{References}

Ainee, A. (2016). Derivation of Tidal Constituents from Satellite Altimetry Data for Coastal Vulnerability Assessment in Malaysia. MSc Thesis. Universiti Teknologi Malaysia, Skudai.

Alihan, N.S.A. (2018). Estimation of Geophysical Loadings over the Malaysian Region Based on Kinematic Precise Point Positioning GPS Technique. MSc Thesis. Universiti Teknologi Malaysia, Skudai.

Cazenave, A. (2019). Satellite Altimetry. Ed(s): J. Kirk Cochran, Henry J. Bokuniewicz, Patricia L. Yager, Encyclopedia of Ocean Sciences (Third Edition), Academic Press, Pages 397-401, ISBN 9780128130827. https://doi.org/10.1016/B978-0-12-4095489.11624-0.

Chambers, D.P. (2015). 3.05 - Gravimetric Methods - Satellite Altimeter Measurements. Ed(s): Schubert, G., Treatise on Geophysics (Second Edition), Elsevier, Pages 117-149, ISBN 9780444538031, https://doi.org/10.1016/B978-0-444-53802-4.00063-4. 
Codiga, D.L., (2011). Unified Tidal Analysis and Prediction Using the UTide Matlab Functions. Technical Report 2011-01. Graduate School of Oceanography, University of Rhode Island, Narragansett, RI. ftp://www.po.gso.uri.edu/pub/downloads/codiga/pubs/2011Codiga-UTide-Report.pdf Courtier, A.-M., (1938). Marées. Service Hydrographique de la Marine, 284 pp.

Daher, V.B., Paes, R.C. de O.V., França, G.B., Alvarenga, J.B.R., and Teixeira, G.L.G., (2015). Extraction of tide constituents by harmonic analysis using altimetry satellite data in the Brazilian coast. J. Atmos. Ocean. Technol. 32, 614-626. https://doi.org/10.1175/JTECH-D-14-00091.1

Daryabor F, Ooi SH, Abu Samah A, Akbari A (2016) Tides and Their Dynamics over the Sunda Shelf of the Southern South China Sea. PLoS ONE 11(9): e0162170. https://doi.org/10.1371/journal.pone.0162170

Din, A.H.M., Ses, S., Omar, K.M., Naeije, M., Yaakob, O., and Pa'suya, M.F., (2014). Derivation of sea level anomaly based on the best range and geophysical corrections for Malaysian seas using radar altimeter database system (RADS). J. Teknol. 71, 8391. https://doi.org/10.11113/jt.v71.3830

Din, A.H.M., Hamid, A.I.A., Yazid, N.M., Tugi, A., Khalid, N.F., Omar, K.M., and Ahmad, A., (2017). Malaysian sea water level pattern derived from 19 years tidal data. J. Teknol. 79, 137-145. https://doi.org/10.11113/jt.v79.9908

Din, A.H.M., Zulkifli, N.A., Hamden, M.H., and Aris, W.A.W., (2019). Sea level trend over Malaysian seas from multi-mission satellite altimetry and vertical land motion corrected tidal data. Adv. Sp. Res. 63, 3452-3472. https://doi.org/10.1016/j.asr.2019.02.022

Feng, G. and Jin, S. (2015). Sea Level Changes Along Global Coasts from Satellite Altimetry, GPS and Tide Gauge, Satellite Positioning - Methods, Models and Applications, Shuanggen Jin, IntechOpen, DOI: 10.5772/58972.

Fok, H. S. (2012). Ocean Tides Modeling using Satellite Altimetry. Doctor of Philosphy, The Ohio State University, Columbus, Ohio 43210.

Fu, Y., Zhou, D., Zhou, X., Sun, Y., Li, F., and Sun, W., (2020). Evaluation of satellite-derived tidal constituents in the South China Sea by adopting the most suitable geophysical correction models. J. Oceanogr. 76, 183-196. https://doi.org/10.1007/s10872-01900537-2

Fu, L., and Cazenave. A. (2001). Satellite Altimetry and Earth Sciences: A Handbook of Techniques and Applications. Academic Press. San Diego, California, ISBN 0122695423.

Gunathilaka, M.D.E.K. and Mahmud, M. R. (2014). Ceaseless Tidal Zoning for Straits of Malacca using Spatial Interpolation. FIG Congress 2014 Engaging the Challenges Enhancing the Relevance Kuala Lumpur, Malaysia 16-21 June 2014.

Hamid, A.I.A., Din, A.H.M., Hwang, C., Khalid, N.F., Tugi, A., and Omar, K.M. (2018). Contemporary sea level rise rates around Malaysia: Altimeter data optimization for assessing coastal impact. J. Asian Earth Sci. 166, 247-259. https://doi.org/10.1016/j.jseaes.2018.07.034

Hoe, T.S. (1996). The Malaysian Sea Level Monitoring Network. GLOSS Bulletin Issue 3. Available at https://www.psmsl.org/train_and_info/training/gloss/gb/gb3/edit.html (accessed 1 January 2021).

Kamaruddin, A.H., Din, A.H.M., Pa'Suya, M.F., and Omar, K.M., (2017). Long-term sea level trend from tidal data in Malaysia, in: 2016 7th IEEE Control and System Graduate Research Colloquium, ICSGRC 2016 - Proceeding. IEEE, pp. 187-192. https://doi.org/10.1109/ICSGRC.2016.7813325 
Katznelson, Y. (2004). An Introduction to Harmonic Analysis. $3^{\text {rd }}$ Edition. United Kingdom: Cambridge University Press.

Pirooznia, M., Emadi, S.R., and Alamdari, M.N., (2016). The Time Series Spectral Analysis of Satellite Altimetry and Coastal Tide Gauges and Tide Modeling in the Coast of Caspian Sea. Open J. Mar. Sci. 06, 258-269. https://doi.org/10.4236/ojms.2016.62021

Salameh E, Frappart F, Marieu V, Spodar A, Parisot J-P, Hanquiez V, Turki I, Laignel B. Monitoring Sea Level and Topography of Coastal Lagoons Using Satellite Radar Altimetry: The Example of the Arcachon Bay in the Bay of Biscay. Remote Sensing. 2018; 10(2):297. https://doi.org/10.3390/rs10020297

Scharroo, R., Leuliette, E. W., Lillibridge, J. L., Byrne, D., Naeije, M. C., and Mitchum, G. T. (2013). RADS: Consistent multi-mission products. In Proc. of the Symposium on 15 Years of Progress in Radar Altimetry (Vol. 20, p. 4). Available at https://www.researchgate.net/profile/RemkoScharroo/publication/262964278_RADS_ Consistent_multi-mission_products/links/0f317539b2660407c6000000/RADSConsistent-multi-mission-products.pdf (Accessed 3 November, 2020).

Soltanpour, A., Pirooznia, M., Aminjafari, S., and Zareian, P. (2018). Persian Gulf and Oman sea tide modeling using satellite altimetry and tide gauge data (TM-IR01), Marine Georesources \& Geotechnology, 36:6, 677-687, DOI:10.1080/1064119X.2017.1366608

Thomson, R.E., and Emery, W.J. (2014). Data Analysis Methods in Physical Oceanography. Edition 3. Amsterdam. The Netherlands: Elsevier.

Wijaya, D.D. (2012). Pengantar Fourier Series. Unpublished note. Kelompok Keilmuan Geodesi, Institut Teknologi Bandung, Indonesia. 